\title{
The effect of exogenous glucose infusion on early embryonic development in lactating dairy cows
}

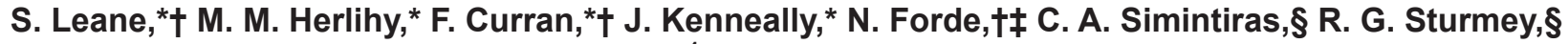 \\ M. C. Lucy,\# P. Lonergan, $†$ and S. T. Butler*1 \\ *Animal and Grassland Research and Innovation Centre, Teagasc, Moorepark, Fermoy, Co. Cork, P61 P302 Ireland \\ †School of Agriculture and Food Science, University College Dublin, Dublin 4, D04 V1W8 Ireland \\ ‡Division of Reproduction and Early Development, Leeds Institute of Cardiovascular and Metabolic Medicine, \\ Faculty of Medicine and Health Science, University of Leeds, Leeds, LS2 9JT, United Kingdom \\ $\S$ Center for Cardiovascular and Metabolic Research, Hull York Medical School, University of Hull, Hull, HU6 7RX, United Kingdom \\ \#Division of Animal Sciences, University of Missouri, Columbia 65211
}

\section{ABSTRACT}

The objective of this study was to examine the effect of intravenous infusion of glucose on early embryonic development in lactating dairy cows. Nonpregnant, lactating dairy cows $(\mathrm{n}=12)$ were enrolled in the study $(276 \pm 17 \mathrm{~d}$ in milk). On d 7 after a synchronized estrus, cows were randomly assigned to receive an intravenous infusion of either $750 \mathrm{~g} / \mathrm{d}$ of exogenous glucose (GLUC; $78 \mathrm{~mL} / \mathrm{h}$ of $40 \%$ glucose wt/vol) or saline (CTRL; $78 \mathrm{~mL} / \mathrm{h}$ of $0.9 \%$ saline solution). The infusion period lasted $7 \mathrm{~d}$ and cows were confined to metabolism stalls for the duration of the study. Coincident with the commencement of the infusion on d 7 after estrus, 15 in vitro-produced grade 1 blastocysts were transferred into the uterine horn ipsilateral to the corpus luteum. All animals were slaughtered on d 14 to recover conceptuses, uterine fluid, and endometrial tissue. Glucose infusion increased circulating glucose concentrations $(4.70 \pm 0.12$ vs. $4.15 \pm 0.12 \mathrm{mmol} / \mathrm{L})$ but did not affect milk production or dry matter intake. Circulating $\beta$-hydroxybutyrate concentrations were decreased ( 0.51 \pm 0.01 vs. $0.70 \pm 0.01 \mathrm{mmol} / \mathrm{L}$ for GLUC vs. CTRL, respectively) but plasma fatty acids, progesterone, and insulin concentrations were unaffected by treatment. Treatment did not affect either uterine lumen fluid glucose concentration or the mRNA abundance of specific glucose transporters in the endometrium. Mean conceptus length, width, and area on d 14 were reduced in the GLUC treatment compared with the CTRL treatment. A greater proportion of embryos in the CTRL group had elongated to all length cut-off measurements between 11 and $20 \mathrm{~mm}$ (measured in 1-mm increments) compared with the GLUC treatment. In conclusion,

Received April 7, 2018.

Accepted July 23, 2018.

${ }^{1}$ Corresponding author: stephen.butler@teagasc.ie infusion of glucose into lactating dairy cows from $\mathrm{d} 7$ to d 14 post-estrus during the critical period of conceptus elongation had an adverse impact on early embryonic development.

Key words: glucose, embryo development, conceptus elongation, uterine environment

\section{INTRODUCTION}

Dairy cows require glucose as a primary metabolic fuel for many tissues. The digestive tract of ruminants is specifically adapted to the digestion of forages. Microorganisms in the rumen ferment carbohydrates to VFA that can be oxidized for energy or used as substrates for synthesizing other molecules. It is estimated that $72 \mathrm{~g}$ of glucose is required for each kilogram of milk produced (Bell, 1995). Although glucose can be a major product of carbohydrate digestion in the rumen, it is rapidly fermented to VFA. Glucose, therefore, must be resynthesized in the liver via gluconeogenesis. This is a crucial process to support glucose homeostasis in the lactating dairy cow (Aschenbach et al., 2010).

Glucose stimulates insulin release from the pancreas, and insulin promotes partitioning of nutrients toward adipose tissue and muscle (Lucy et al., 2014). Insulin in turn stimulates the liver to release IGF1 into circulation (Butler et al., 2003), and IGF1 concentrations during early lactation are positively associated with subsequent fertility (Patton et al., 2007). Reduced blood glucose concentrations in early lactation may be detrimental for fertility and embryo survival (Lucy et al., 2013). Circulating glucose concentrations were greater in heifers (Rizos et al., 2010) and postpartum nonlactating dairy cows (Green et al., 2012; Maillo et al., 2012; Forde et al., 2016) compared with postpartum lactating dairy cows. Greater blood concentrations of glucose at wk 3 and 4 postpartum have been associated with shorter days to pregnancy (Cardoso et al., 2013). 
Similarly, cows that became pregnant to first insemination had greater blood glucose concentrations compared with those that did not become pregnant (Green et al., 2012; Garverick et al., 2013). Moore et al. (2014) reported that glucose concentrations were greater in cows with good genetic merit for fertility (Fert+) than in cows with poor genetic merit for fertility traits (Fert-) during the early postpartum period.

The mammalian embryo undergoes marked changes in morphology and energy requirements as it develops through the early cleavage divisions to form a blastocyst. Following hatching, the embryo progresses through ovoid, tubular, and then filamentous stages of development. In vivo, preimplantation mammalian embryos develop in a complex milieu of nutrients, ions, and macromolecules (Bazer et al., 2012; Forde et al., 2014a,b). Like most mammalian cells, preimplantation embryos derive their ATP predominantly by oxidative phosphorylation, initially from pyruvate, lactate, and amino acids (Leese, 2012). After morula compaction, glucose becomes an important substrate but in quantitative terms makes only a modest contribution to ATP generation. In general, throughout pre-elongation development, embryos rely on oxidative phosphorylation via oxidation of pyruvate and amino acids for the generation of ATP for embryo development (Javed and Wright, 1991; Rieger et al., 1992). There is, however, a switch to an increased contribution from glycolysis during compaction and blastulation (Thompson et al., 1996).

The studies described above are associative, linking relationships between early postpartum blood concentrations of glucose and the establishment of pregnancy several months later. The direct effect of elevating circulating glucose concentrations on contemporaneous early embryo development in vivo has not been previously reported. Therefore, the aim of this study was to evaluate the effects of intravenous glucose infusion on embryo development in lactating dairy cows during the period of blastocyst hatching and elongation, a critical phase leading to maternal recognition of pregnancy (Forde et al., 2011b). We used an established model of multiple embryo transfer (O'Hara et al., 2012) to test the hypothesis that supplemental glucose would accelerate conceptus elongation between $\mathrm{d} 7$ and 14 of gestation.

\section{MATERIALS AND METHODS}

\section{Animals and Treatments}

The experimental procedures involving animals in this study were approved by the Teagasc Animal Ethics Committee and licensed by the Department of Health, Ireland, in accordance with the Cruelty to Animals Act (Ireland 1876) and the European Community Directive $86 / 609 /$ EEC. The study was undertaken at Teagasc Moorepark from November 2014 to December 2014. A schematic outline of the experimental timeline is illustrated in Figure 1.

Nonpregnant, late-lactation dairy cows $(\mathrm{n}=12)$ that had previously been managed in a grazing-based system with moderate milk production were enrolled in the study (276 $\pm 17 \mathrm{DIM})$. The average parity was $3.0 \pm 0.8$ (mean $\pm \mathrm{SD}$ ). Cows were submitted to a hormonal protocol for synchronization of ovulation

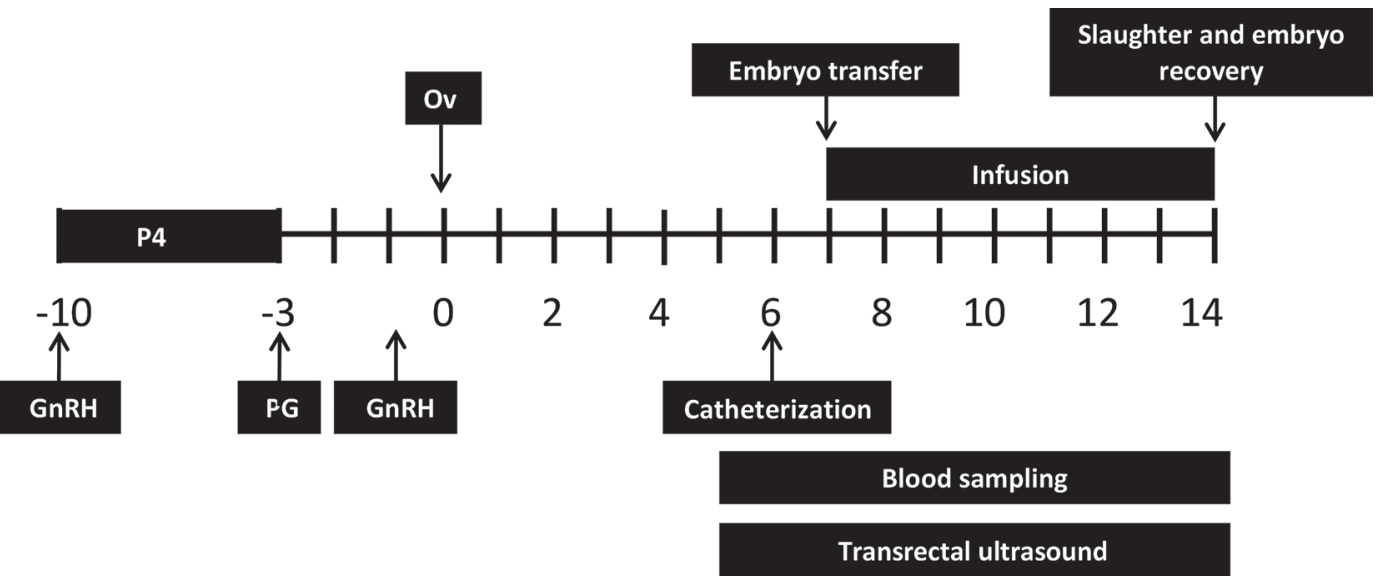

Figure 1. The estrous cycle of late-lactation dairy cows was synchronized using a progesterone (P4)-releasing intravaginal device with administration of gonadotropin-releasing hormone $(\mathrm{GnRH})$ at device insertion and prostaglandin $\mathrm{F}_{2 \alpha}(\mathrm{PG})$ at device removal. A second $\mathrm{GnRH}$ injection was administered $56 \mathrm{~h}$ after device removal on $\mathrm{d}-1$ to ensure ovulation (Ov) of dominant follicles. Transrectal ultrasound was carried out on d $-1,1,4,8,11$, and 14 to evaluate ovarian activity. Blood samples were taken on $\mathrm{d} 5$ and 6 for pre-experimental baseline values and every $12 \mathrm{~h}$ from d 7 to 14 . Fifteen in vitro-produced blastocysts were transferred into each cow $(\mathrm{n}=12)$ on d 7 . Glucose and saline infusion treatments lasted from d 7 to 14 . All animals were slaughtered on d 14 and reproductive tracts were recovered. 
using a 7-d progesterone-releasing intravaginal device (PRID E, Ceva Santé Animale, Libourne, France), with administration of prostaglandin $\mathrm{F}_{2 \alpha}$ (dinoprost, $5 \mathrm{~mL}$; Enzaprost, Ceva Santé Animale) at device removal. Gonadotropin-releasing hormone (gonadorelin diacetate, $2 \mathrm{~mL}$; Ovarelin, Ceva Santé Animale) was administered at PRID insertion $(\mathrm{d}-10)$ and at $56 \mathrm{~h}$ after PRID removal $(\mathrm{d}-1)$.

On d 6 following presumptive estrus (d 0), bilateral indwelling jugular catheters were inserted (Tygon Microbore Tubing; Norton Performance Plastic, Akron, $\mathrm{OH})$; one catheter was used for infusion of solutions (glucose or saline) and the contralateral catheter was used to collect blood samples. On d 7 following presumptive estrus, cows were blocked on the basis of DIM, average milk yield during the previous $2 \mathrm{wk}$, and $\mathrm{BCS}$, and were randomly assigned to receive intravenous infusion of either $750 \mathrm{~g} / \mathrm{d}$ of exogenous glucose (GLUC; $78 \mathrm{~mL} / \mathrm{h}$ of $40 \%$ glucose, wt/vol; Serumwerk Bernburg, Bernburg, Germany) or saline (CTRL; 78 $\mathrm{mL} / \mathrm{h}$ of $0.9 \%$ saline solution; Dechal Ltd., Staffordshire, UK). The infusion period lasted $7 \mathrm{~d}$, and cows were confined to individual metabolism stalls for the duration of the study. Body temperature was recorded twice daily for the duration of the study to monitor animal health.

\section{In Vitro Embryo Production}

Immature cumulus-oocyte complexes (COC) were obtained by aspirating follicles from ovaries collected at slaughter. The COC were matured for $24 \mathrm{~h}$ in TCM-199 supplemented with $10 \%$ (vol/vol) fetal calf serum (FCS; Sigma, Arklow, Ireland) and $10 \mathrm{ng} / \mathrm{mL}$ epidermal growth factor at $39^{\circ} \mathrm{C}$ in an atmosphere of $5 \% \mathrm{CO}_{2}$ in air with maximum humidity. Matured $\mathrm{COC}$ were inseminated with frozen-thawed Percoll-separated motile bull sperm. Gametes were co-incubated at $39^{\circ} \mathrm{C}$ in an atmosphere of $5 \% \mathrm{CO}_{2}$ in air with maximum humidity. Semen from the same bull was used throughout. At approximately $20 \mathrm{~h}$ after insemination, presumptive zygotes were denuded of surrounding cumulus cells and accessory sperm and cultured in $50 \mathrm{~mL}$ of synthetic oviduct fluid supplemented with $5 \%$ FCS until d 7 .

\section{Embryo Transfer and Recovery}

Day 7 grade 1 blastocysts were loaded into straws for transfer to the uterine horn ipsilateral to the corpus luteum (CL) of synchronized recipients (15 transferred per recipient). Embryos were transferred on $\mathrm{d} 7$ of the estrous cycle concomitant with the commencement of the infusion treatments. On d 14, infusion pumps were turned off at $0700 \mathrm{~h}$. The cows were then transported to an abattoir and all animals were slaughtered before $1200 \mathrm{~h}$. The reproductive tracts were recovered and placed in labeled bags in a cooler, before transport to the laboratory for processing. On arrival at the laboratory, both the ipsilateral and contralateral uterine horns were flushed with $10 \mathrm{~mL}$ of PBS. The number of embryos recovered and the dimensions (length and width) of each recovered embryo were recorded. Each CL was dissected free of ovarian tissue, weighed, and its diameter measured. Uterine flush from the ipsilateral and contralateral uterine horns was centrifuged at $1,000 \times g$ at $4^{\circ} \mathrm{C}$; then, the supernatant was removed and snap frozen in individual $1-\mathrm{mL}$ aliquots and stored at $-80^{\circ} \mathrm{C}$. A further $10-\mathrm{mL}$ flush was performed on each of the uterine horns to ensure all conceptuses were recovered. A sample of inter-caruncular endometrial tissue was dissected from the underlying myometrium in strips, placed into RNase-/DNase-free tubes, snap frozen in liquid nitrogen, and stored at $-80^{\circ} \mathrm{C}$.

\section{Plasma Measurements}

Pretreatment blood samples were collected on d 4 and 6 from the coccygeal vessels using 21-gauge Vacutainer needles into $10-\mathrm{mL}$ lithium heparin Vacutainer tubes (Becton Dickinson, Plymouth, UK). During the infusion period, blood samples were collected via the jugular catheter at 0600 and $1800 \mathrm{~h}$ and decanted into 10-mL lithium heparin Vacutainer tubes. All blood samples were immediately centrifuged at $1,500 \times g$ for 15 min at $4^{\circ} \mathrm{C}$; the plasma was harvested and stored at $-20^{\circ} \mathrm{C}$ until later analysis. Plasma samples collected were analyzed for concentrations of fatty acids (FA), BHB, and glucose by enzymatic colorimetry using an ABX Pentra 400 autoanalyser (ABX Mira, Montpellier, France; NEFA kit supplied by Wako Chemicals GmBH, Germany; BHB kit supplied by Randox Laboratories Limited, Crumlin, UK; Glucose kit supplied by Horiba ABX, Montpellier, France). Concentrations of insulin and progesterone were determined by solid-phase RIA (Coat-A-Count Insulin, Diagnostic Products Corp., Los Angeles, CA; and DIAsource ImmunoAssays S.A. Louvain-la-Neuve, Belgium). Inter- and intra-assay coefficients of variation were $1.96 \%$ and $4.32 \%$, respectively, for insulin and $6.78 \%$ and $8.90 \%$ for progesterone.

\section{Milk Yield and Composition and DMI}

Cows were milked twice daily at 0800 and $1600 \mathrm{~h}$. Milk yield was recorded at each milking using electronic milk meters (Dairymaster, Causeway, Co. Kerry, Ireland). Milk composition (fat, protein, and lactose) was determined 3 times during the infusion period from successive p.m. and a.m. samples by mid-infrared re- 
flectance spectroscopy (FT6000 Milkoscan instrument, Foss Electric, Hillerød, Denmark).

Feed was offered ad libitum throughout the study period. The diet consisted of perennial ryegrass silage, maize silage, and concentrates. The TMR was $18.9 \%$ CP, $2.3 \%$ oil, $7.3 \%$ ash, and $38.1 \%$ NDF. Dry matter intake was calculated daily for the 7 -d infusion period.

\section{Transrectal Ultrasound}

The reproductive tracts of all cows were examined before initiation of the synchronization protocol by transrectal ultrasound using a linear array probe (Ibex Pro scanner with an 8.5-MHz transducer, E.I. Medical Imaging, Loveland, CO) to verify absence of abnormalities. Transrectal ultrasound scanning was carried out on $\mathrm{d}-1,1,5,8,11$, and 14 relative to induced estrus to evaluate ovarian activity and to assess CL development. The clearest image of the CL was captured, and the cross-sectional height and width were measured using the internal caliper on the ultrasound machine. Corpus luteum volume (V) was calculated using the formula $\mathrm{V}=4 / 3 \pi \mathrm{r}^{3}$, where $\mathrm{r}=$ radius.

\section{RNA Extraction and cDNA Synthesis}

Total RNA was extracted from endometrial tissue using a standard Trizol-based method (Chomczynski and Sacchi, 1987). The tissue sample was weighed and 100 $\mathrm{mg}$ was homogenized in $1 \mathrm{~mL}$ of TRI Reagent (SigmaAldrich, Dublin, Ireland) for $2 \mathrm{~min}$ at $30 \mathrm{~Hz}$ using a Qiagen tissue lyser (Qiagen, Manchester, UK). The homogenate was removed to sterile Eppendorf tubes; then, $0.1 \mathrm{~mL}$ of bromo-chloropropane (Sigma-Aldrich) was added to the tubes and the samples were vortexed, incubated at room temperature for $3 \mathrm{~min}$, and centrifuged at $12,000 \times g$ for $15 \mathrm{~min}$ at $4^{\circ} \mathrm{C}$. The supernatant was removed to new sterile tubes. Isopropanol was added at 0.6 times the volume of supernatant, vortexed, and centrifuged at $12,000 \times g$ for $10 \mathrm{~min}$ at $4^{\circ} \mathrm{C}$ to pellet the RNA. The supernatant was discarded and the pellet was washed twice in 99\% ethanol (Sigma-Aldrich) followed by centrifugation at $7,500 \times g$ for 5 min at $4^{\circ} \mathrm{C}$. The RNA was resuspended in $35 \mu \mathrm{L}$ of nuclease-free water (Sigma-Aldrich). A kit-based protocol (RNeasy, Qiagen) as well as on-column DNase digestion were used to clean the total RNA, removing the fraction $<200 \mathrm{bp}$. The quality and concentration of RNA were determined using the Nanodrop ND-1000 (Nanodrop, Wilmington, DE) and the Bioanalyser 2100 (Agilent Technologies, Cheadle, UK) using the RNA Nano chip. The $260 \mathrm{~nm} / 280 \mathrm{~nm}$ absorbance ratio ranged between 2.0 and 2.1 for all samples. Subsequently, $500 \mathrm{ng}$ of RNA was reverse transcribed to cDNA using the High-
Capacity cDNA Reverse Transcription kit (Applied Biosystems, Foster City, CA) per the manufacturer's instructions to synthesize $\mathrm{cDNA}$ in a $20-\mu \mathrm{L}$ reaction, diluted to $1 \mathrm{ng} / \mu \mathrm{L}$ of RNA equivalents with water and stored at $-20^{\circ} \mathrm{C}$.

\section{Primer Design and Reference Gene Selection}

Primers were designed to span exon-exon junctions where possible and PCR product size was restricted to between 50 and 155 nucleotides, using the National Center for Biotechnology Information (NCBI) PrimerBlast; (http://www.ncbi.nlm.nih.gov/tools/primer -blast/). All primers were manufactured by Eurofins MWG (Ebersberg, Germany). The geNorm application within the Biogazelle qBaseplus software program (www.qbaseplus.com; Biogazelle, Ghent, Belgium) determined that succinate dehydrogenase complex flavoprotein subunit A $(S D H A)$ and ring finger protein 11 ( $R N F 11$ ) combined were the most stably expressed reference genes, with an geNorm M-value of 0.23 . The expected product sizes for all primers were confirmed by gel electrophoresis.

\section{Real-Time Quantitative PCR}

Using real-time quantitative PCR analysis, the endometrial expression of 5 target genes was determined (Table 1). All PCR reactions were performed in a 20.0$\mu \mathrm{L}$ reaction consisting of $5 \mu \mathrm{L}(5 \mathrm{ng})$ of $\mathrm{cDNA}, 10 \mu \mathrm{L}$ of SYBR MasterMix (Bioline, Medical Supply Company, Dublin, Ireland), and $1.2 \mu \mathrm{L}$ of forward and reverse primers on clear 96-well plates (FrameStar, 4titude Limited, Surrey, UK). All samples were measured in duplicate. Primer efficiencies for each target were determined using a 1-in-4 serial dilution over 7 points and were shown to lie between 90 and $110 \%$; nontemplate controls and minus RT controls were included for each target. All reactions were run on a 7500 Real-Time PCR machine (Applied Biosystems) with the following cycling conditions: $50^{\circ} \mathrm{C}$ for $2 \mathrm{~min}, 95^{\circ} \mathrm{C}$ for $10 \mathrm{~min}$, 40 cycles of $95^{\circ} \mathrm{C}$ for $15 \mathrm{~s}, 60^{\circ} \mathrm{C}$ for $1 \mathrm{~min}$, followed by $95^{\circ} \mathrm{C}$ for $15 \mathrm{~s}, 60^{\circ} \mathrm{C}$ for $1 \mathrm{~min}$ and $95^{\circ} \mathrm{C}$ for $15 \mathrm{~s}$ to create a dissociation curve, which was examined to ensure amplification was specific to the target gene. Relative gene expression values (calibrated normalized relative quantity, CNRQ) were determined using the qBase software package (Biogazelle).

\section{Substrate Analysis of Uterine Luminal Fluid}

Concentrations of glucose, lactate, and pyruvate in the uterine luminal fluid were determined using specific enzyme-linked fluorometric assays, based on the meth- 
Table 1. Oligonucleotide primer sequence information used for real-time quantitative PCR assays

\begin{tabular}{lll}
\hline Gene & Primer sequence $\left(5^{\prime}\right.$ to $\left.3^{\prime}\right)$ & Accession number \\
\hline SLC2A1 & Forward: CGGCATCAACGCTGTTTTCT (20) & NM_174602 \\
& Reverse: GAAGGCTGTGTTGACGATGC (20) & \\
SLCA3 & Forward: CCCTCGGCCGCGTTCTA (17) & NM_174603 \\
& Reverse: TTCCTCAAAAGTCCTGCCACG (21) & \\
& Forward: TGGCCCCGGTCTATATCTCT (20) & NP_963286 \\
SLC5A1 & Reverse: GCTAGGAGGATGCCTGTGAC (20) & NM_174606 \\
SLC35A4 & Forward: CTACGAGCGCATCCGCAAT (19) & NM_001079612 \\
& Foverse: AGTGGAAAACATGGCCCACA (20) & \\
\hline
\end{tabular}

ods described by Guerif et al. (2013). Glucose, pyruvate, and lactate were individually and indirectly quantified by enzymatic conversion to produce a nicotinamide byproduct that was spectrophotometrically detected using a FLUOstar Omega micro-plate reader (BMG LabTech, Ortenberg, Germany) in a method similar to that of Leese (1983), Leese and Barton (1984), Gardner and Leese (1990), and Guerif et al. (2013). Samples were diluted to fit within the standard curves and the initial concentration of substrate was calculated by comparing resulting fluorescence intensity against a standard curve while accounting for dilution.

\section{Data Analysis}

All data handling and analysis was performed using SAS software (version 9.3; SAS Institute Inc., Cary, NC) Sixteen cows were synchronized before the study commenced. Cows were deemed to have had a synchronized ovulation if the preovulatory follicle measured on d 0 ovulated and formed a CL. Of the 16 synchronized cows, 12 were enrolled in this study. Records of 1 CTRL cow were removed from the statistical analysis due to ill health unrelated to the experimental treatment. Data were checked for normality and, where necessary, suitable Box-Cox transformations were identified using the TRANSREG procedure to normalize the distribution of BHB, FA, and mRNA abundance of members of the solute carrier family of genes (SLC2A1, SLC2A3, SLC2A8, SLC35A4, and SLC5A1). The distribution of progesterone data was normalized by natural logarithm transformation, and back-transformed results are reported as progesterone concentration with $95 \%$ confidence intervals. Continuous data were analyzed using mixed models procedures. Where repeated measures were conducted on the same animal, data were analyzed using mixed models procedures with repeated measures, with a first-order autoregressive covariance structure applied. The model included treatment, time, and parity as fixed effects, and all possible interactions were investigated and retained in the final model if significant $(P<0.1)$. The Tukey adjustment was included to correct for multiple comparison tests. The BCS and pre-experimental measurements recorded before the infusions began were included as covariate adjustments, and block was included as a random effect. For each cow, the proportion of embryos recovered that had elongated to increasing lengths was assessed in 1 - $\mathrm{mm}$ increments between 2 and $20 \mathrm{~mm}$ (i.e., if 5 out of 10 embryos recovered were $16 \mathrm{~mm}$ or longer, then the proportion of embryos $\geq 16 \mathrm{~mm}$ was 0.5 ). These data were analyzed using a generalized linear mixed model with a Poisson distribution. Treatment and parity were included in the model as fixed effects, and block was included as a random effect.

\section{RESULTS}

\section{Blood Metabolites and Insulin}

The effects of exogenous glucose infusion on circulating glucose, BHB, and plasma FA concentrations from d 4 to 14 of the study are illustrated in Figure 2. During the infusion period, circulating glucose concentrations were elevated in GLUC cows compared with CTRL cows $(+0.55 \mathrm{mmol} / \mathrm{L} ; P<0.001)$. The GLUC treatment reduced circulating BHB concentrations $(-0.19$ $\mathrm{mmol} / \mathrm{L}, P=0.01$ ), but neither circulating insulin nor plasma FA concentration was affected by treatment.

\section{Milk Production, DMI, and Body Temperature}

The effects of exogenous glucose infusion on milk production and DMI are illustrated in Figure 3. During the infusion period, average milk production (14.1 vs. $14.8 \pm 1.3 \mathrm{~kg} / \mathrm{d} ; P=0.26)$ and DMI (15.0 vs. $14.4 \pm 0.9$ $\mathrm{kg} / \mathrm{d} ; P=0.57)$ were not different between GLUC and CTRL cows, respectively. Mean rectal temperature was also not different between treatments $\left(37.92 \pm 0.08^{\circ} \mathrm{C}\right.$ vs. $37.98 \pm 0.08^{\circ} \mathrm{C}$ for GLUC vs. CTRL; $\left.P=0.82\right)$

\section{Uterine Glucose Environment}

The 2 treatment groups did not differ in post-slaughter uterine luminal fluid concentrations of glucose, lactate, 

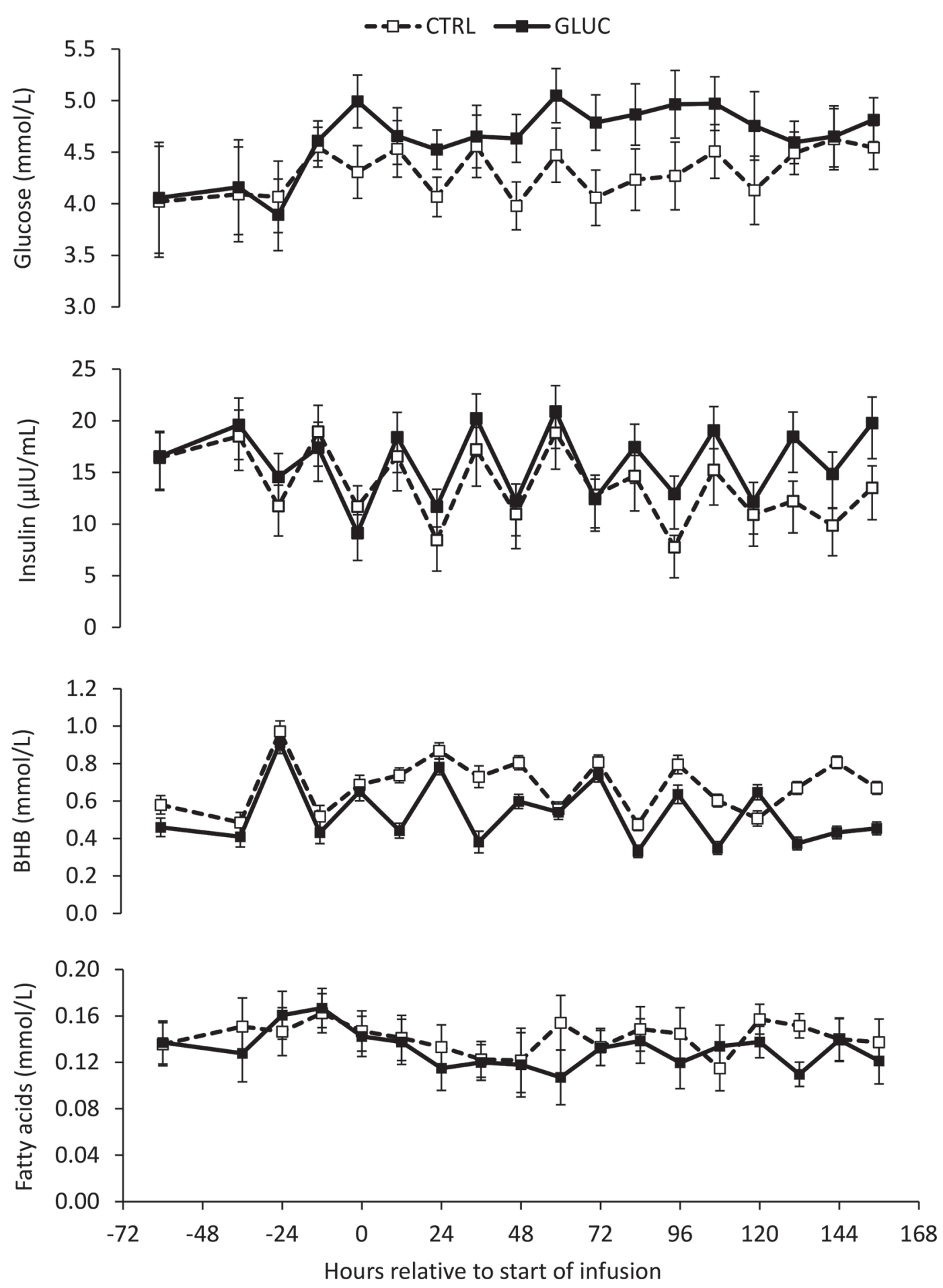

Figure 2. Effect of exogenous glucose (GLUC treatment) on circulating concentrations of glucose, insulin, plasma fatty acids, and BHB in GLUC and control (CTRL) cows during the baseline period ( -60 to $-12 \mathrm{~h}$ relative to start of infusion) and infusion period (0 to $156 \mathrm{~h})$. The GLUC cows received intravenous glucose infusion $(750 \mathrm{~g} / \mathrm{d} ; 78 \mathrm{~mL} / \mathrm{h}$ of $40 \%$ glucose) at a constant rate from $0 \mathrm{~h}$ until $156 \mathrm{~h}$; the CTRL cows received intravenous infusion of saline $(78 \mathrm{~mL} / \mathrm{h}$ of $0.9 \%$ saline solution). Treatment affected glucose $(P<0.001)$ and BHB $(P=0.007)$ concentrations, but did not affect circulating plasma fatty acids $(P>0.08)$. Vertical bars indicate SEM. 
or pyruvate on d 14 of the study (Figure 4, top panel). The mRNA abundance of the glucose transporter genes examined in endometrial tissue samples were also not affected by treatment (Figure 4, bottom panel).

\section{Embryo Recovery and Elongation}

The overall conceptus recovery rate on d 14 was $68 \%$ (i.e., conceptuses recovered as a percentage of embryos transferred, 112/165), and similar recovery rates per cow were recorded for both treatments. The effect of treatment on mean conceptus length, width, and area are illustrated in Figure 5. The proportion of embryos that elongated to different lengths is illustrated in Figure 6. A greater proportion of embryos had elongated to all cut-off length measurements $\geq 11 \mathrm{~mm}$ in the CTRL treatment compared with the GLUC treatment.

\section{Circulating Progesterone Concentrations}

We detected no effect of treatment $(6.9 \pm 1.0$ vs. 6.8 $\pm 1.0 \mathrm{ng} / \mathrm{mL}$, GLUC vs. CTRL, respectively; $P>0.05$ ) or treatment by time interaction for progesterone con-
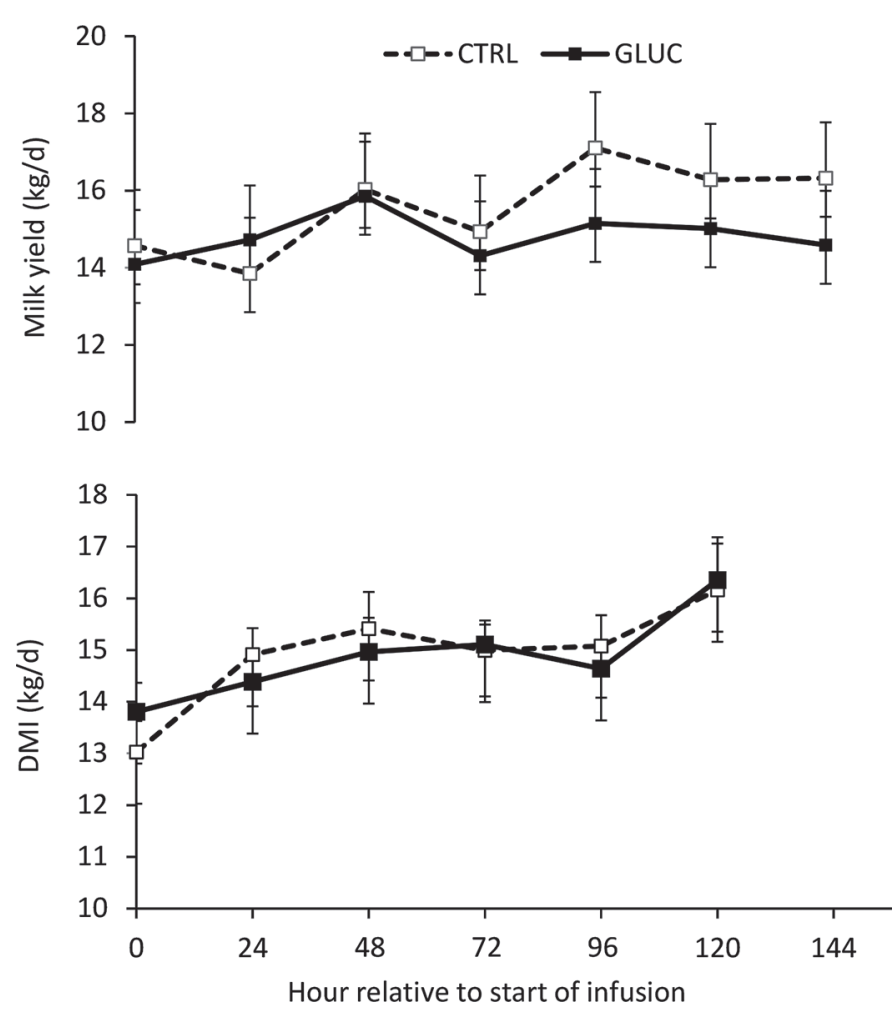

Figure 3. Milk production $(\mathrm{kg} / \mathrm{d})$ and DMI $(\mathrm{kg} / \mathrm{d})$ in treatment (GLUC) and control (CTRL) cows during the 156-h infusion period. The GLUC cows received intravenous glucose infusion $(750 \mathrm{~g} / \mathrm{d} ; 78$ $\mathrm{mL} / \mathrm{h}$ of $40 \%$ glucose) at a constant rate from $0 \mathrm{~h}$ until $156 \mathrm{~h}$; the CTRL cows received intravenous infusion of saline $(78 \mathrm{~mL} / \mathrm{h}$ of $0.9 \%$ saline solution). Treatment did not affect milk production $(P=0.26)$ or DMI $(P=0.57)$. Vertical bars indicate SEM.
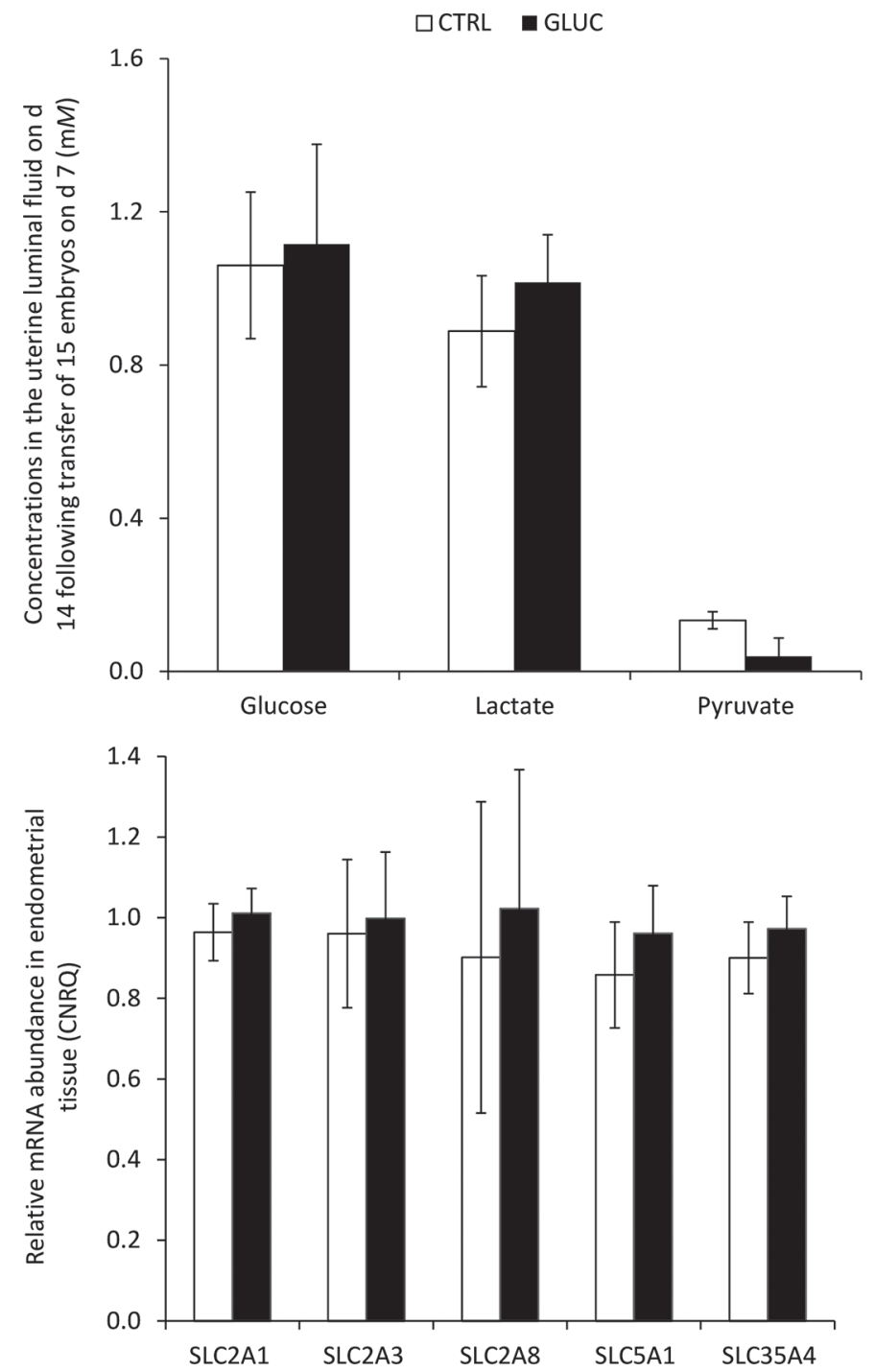

Figure 4. The effect of exogenous glucose infusion (GLUC) on uterine lumen fluid of glucose, lactate, and pyruvate concentrations (top panel) and on endometrial mRNA abundance (calibrated normalized relative quantity, CNRQ) of glucose transporters (bottom panel) on d 14. The GLUC cows received intravenous glucose infusion (750 $\mathrm{g} / \mathrm{d} ; 78 \mathrm{~mL} / \mathrm{h}$ of $40 \%$ glucose) at a constant rate from d 7 to 14 following estrus; the control (CTRL) cows received intravenous infusion of saline $(78 \mathrm{~mL} / \mathrm{h}$ of $0.9 \%$ saline solution). Fifteen in vitro-produced blastocysts were transferred into all cows on $\mathrm{d} 7$. Reproductive tracts were recovered post-slaughter on d 14 . The concentrations of metabolites and mRNA abundance of glucose transporters were similar for both treatments. Vertical bars indicate SEM.

centrations during the study (Figure 7A). There was no effect of treatment on CL volume measured by transrectal ultrasound, but a treatment by time interaction $(P<0.001)$ was detected (Figure 7B). Treatments did not differ in CL weight $(7.1 \pm 0.6$ vs. $7.2 \pm 0.7 \mathrm{~g}$, GLUC vs. CTRL; $P=0.8)$ or CL volume $(5,654 \pm 577$ vs. $5,529 \pm 632 \mathrm{~mm}^{3}$; GLUC vs. CTRL; $\left.P=0.9\right)$ after recovery of the reproductive tract and CL dissection on d 14. 


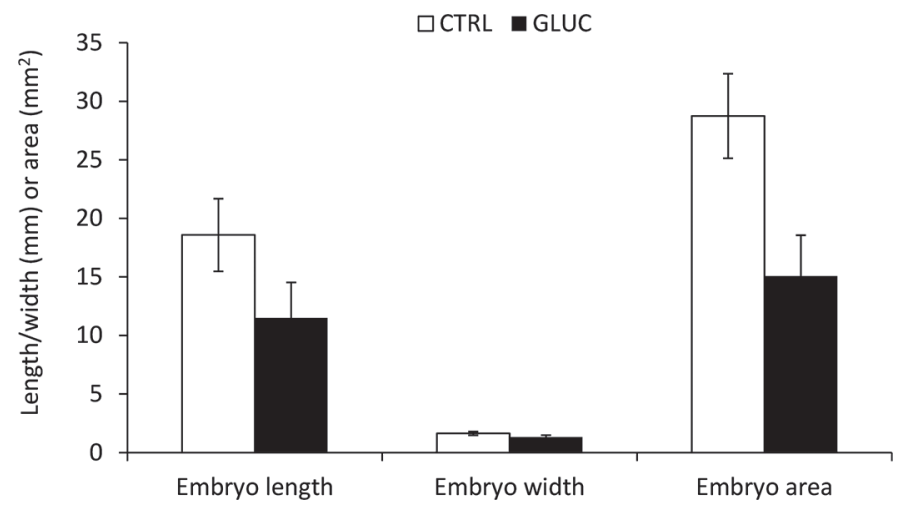

Figure 5. Mean dimensions of conceptuses recovered from uterine flushings on d 14. The GLUC cows received intravenous glucose infusion $(750 \mathrm{~g} / \mathrm{d} ; 78 \mathrm{~mL} / \mathrm{h}$ of $40 \%$ glucose $)$ at a constant rate from $0 \mathrm{~h}$ until $156 \mathrm{~h}$; the control (CTRL) cows received intravenous infusion of saline $(78 \mathrm{~mL} / \mathrm{h}$ of $0.9 \%$ saline solution $)$. Data represent 11 animals and 112 embryos in total. Embryo length $(P=0.025)$, embryo width $(P=0.007)$, and embryo area $(P=0.001)$ were greater in CTRL cows than in GLUC cows. Vertical bars indicate SEM.

\section{DISCUSSION}

This study examined the effects of infusing exogenous glucose on early embryonic development from $\mathrm{d}$ 7 to 14 post-estrus. We hypothesized that increasing circulating concentrations of glucose would accelerate embryo development due to increased availability of energy substrates. The main finding from the current study, however, was that elevating circulating glucose delayed early embryo development.

Infusion of exogenous glucose elevated blood glucose concentrations by approximately $0.55 \mathrm{~m} M$, a physiologically relevant increase. For example, Maillo et al. (2012) and Forde et al. (2016) reported blood glucose concentrations of approximately $4 \mathrm{mM}$ for heifers and nonlactating cows and approximately $3.5 \mathrm{mM}$ for lactating cows. This $0.5 \mathrm{~m} M$ difference between "fertile" and "less fertile" animals is consistent with the difference between groups in the current study. Similarly, Garverick et al. (2013) reported a difference of about 5 $\mathrm{mg} / \mathrm{dL}(0.275 \mathrm{mM})$ during the early postpartum period between cows that subsequently became pregnant and those that did not. Hence, the elevation in circulating glucose achieved was within the range necessary to elicit a physiological response.

Glucose is an important energy substrate for the placenta and fetus, and is essential for normal fetal metabolism and growth (Hay, 2006). Previous studies have shown favorable associations between circulating glucose concentrations, especially during the early postpartum period, and subsequent fertility performance (Green et al., 2012; Moore et al., 2014). Mean glucose concentrations were, or tended to be, greater on d 0,3 ,
7 and 21 postpartum in cows that subsequently became pregnant than in cows that were not pregnant following first insemination (Garverick et al., 2013). Green et al. (2012) examined the effects of lactation on early postpartum nutrient partitioning and the establishment of pregnancy and reported that increased likelihood of pregnancy after first insemination was associated with greater blood glucose and IGF1 during the first 30 d postpartum (Green et al., 2012). Consistent with these studies, circulating glucose concentrations were greater in heifers (Forde et al., 2016) and postpartum nonlactating dairy cows (Maillo et al., 2012; Forde et al., 2016) than in postpartum lactating cows. Collectively, these studies indicate a clear association between greater glucose concentrations and improved fertility performance. To date, however, no studies have been conducted to examine the direct effects of circulating glucose concentrations on in vivo embryo development during the very early stages of pregnancy.

\section{Embryo Growth and Development}

Glucose infusion increased circulating glucose concentrations between $\mathrm{d} 7$ and 14 of the estrous cycle. This increase in glucose concentrations was associated with delayed embryo development as measured by conceptus elongation on d 14. Although this finding disagrees with our original hypothesis, it is consistent with in vitro results reported by Green et al. (2016), who altered glucose metabolism through either glucose supplementation or uncoupling oxidative phosphorylation with 2,4-dinitrophenol (DNP) between d 5 and 8 after in vitro fertilization. In that study, greater glucose concentrations (4.0 vs. $0 \mathrm{mM}$ ) during embryo culture substantially reduced bovine blastocyst development on d 8 (Green et al., 2016). Earlier work by Rieger et al. (1995) suggested that increased rates of glucose metabolism induced by conditioned culture medium were unfavorable for subsequent embryo development. Early embryo development requires energy in the form of ATP, which is produced through 2 possible mechanisms: glycolysis, using glucose as a substrate, or oxidative phosphorylation, using pyruvate, amino acids, or endogenous stores of triglyceride or oxaloacetate as substrates (Harvey et al., 2002). The glycolytic pathway is essential for ATP production; it also plays a significant role in the regulation of reactive oxygen species and may well play a vital anabolic role (Smith and Sturmey, 2013). Lane and Gardner (1996) reported that mouse blastocysts with a high glycolytic rate are less viable after transfer than blastocysts with a low glycolytic rate. Similar data were reported for humans (Gardner et al., 2011). Recent work on in vitro-derived equine embryos indicated that culture medium com- 


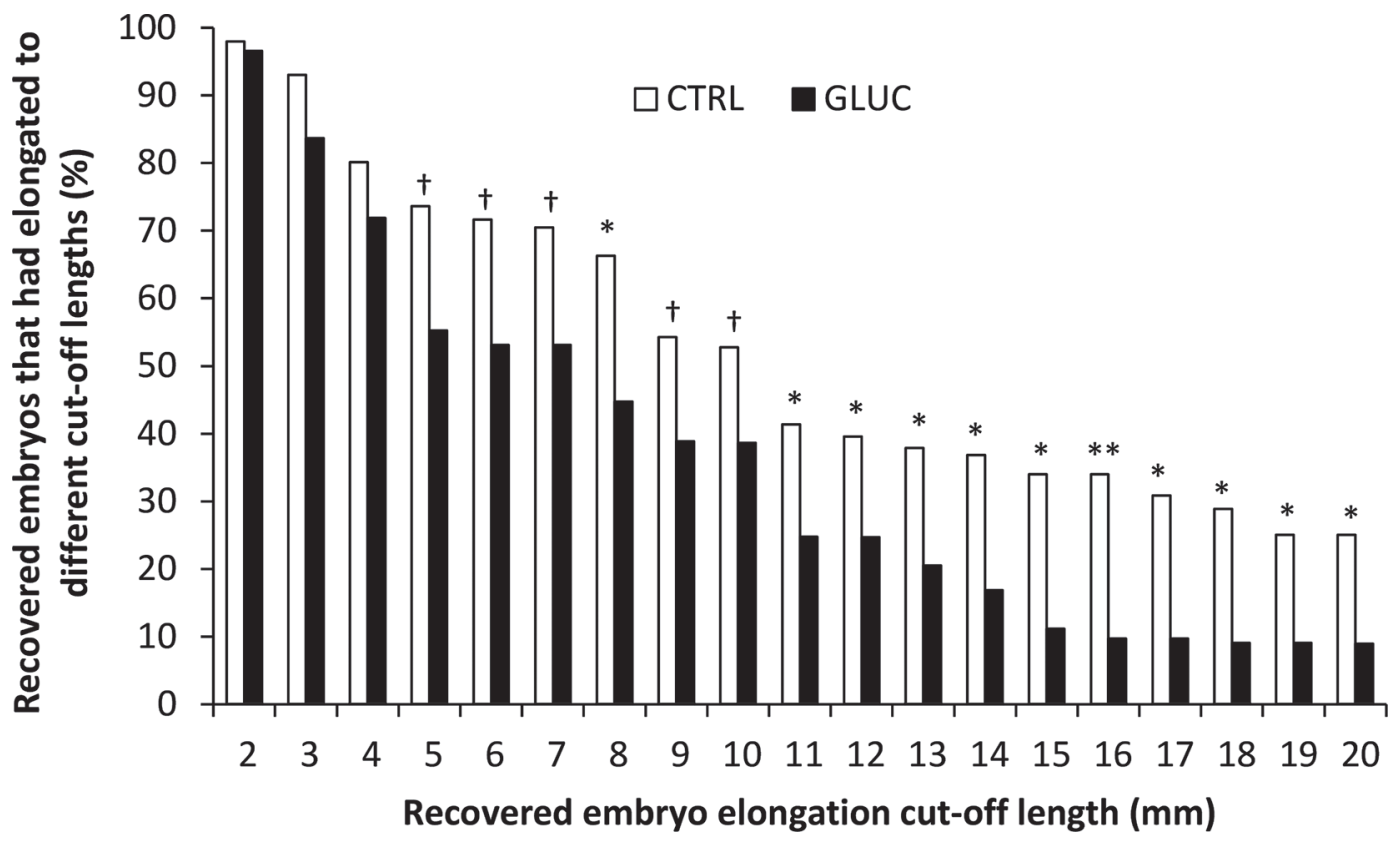

Figure 6. The effect of treatment on embryo elongation. The GLUC cows received intravenous glucose infusion $(750 \mathrm{~g} / \mathrm{d} ; 78 \mathrm{~mL} / \mathrm{h}$ of $40 \%$ glucose solution) at a constant rate from $0 \mathrm{~h}$ until $156 \mathrm{~h}$; the control (CTRL) cows received intravenous infusion of saline (78 $\mathrm{mL} / \mathrm{h}$ of $0.9 \%$ saline solution). The CTRL cows had a greater percentage of recovered embryos that had elongated to all cut-off lengths $\geq 11 \mathrm{~mm}(\dagger P<0.1$, $\left.{ }^{*} P<0.05,{ }^{*} P<0.01\right)$.

position, and in particular glucose concentrations, can affect lineage allocation in the preimplantation embryo (Choi et al., 2016). This may, at least partly, explain why embryo development was reduced in response to increased circulating concentrations of glucose.

There may also be some potential insights from this study of relevance to human reproduction. In the present study, cows were in late lactation and all at least 6 mo past the period of postpartum negative energy balance and associated hypoglycemia. At the time of the study, therefore, cows had normal circulating glucose concentrations and were not in a glucose deficit. Exogenous glucose infusion resulted in GLUC cows moving from normoglycemic status to mild hyperglycemic status. It is well established that women with obesity and type 2 diabetes generally present with hyperglycemia and have less likelihood of conception and greater likelihood of pregnancy loss (Poston et al., 2016). It is plausible to speculate that hyperglycemia during early human pregnancy is directly detrimental to the developing embryo, the uterine environment, or both. The cow may provide a useful model to identify potential mechanisms responsible.

\section{Milk Production and DMI}

Glucose requirements of the dairy cow are primarily the requirements of the mammary gland for milk synthesis (Reynolds, 2005). Increasing glucose absorption will increase glucose supply to the lactating dairy cow but, even in early lactation, the primary metabolic response appears to be an increase in body tissue energy balance rather than an increase in milk energy yield (Reynolds, 2005). We did not observe any effect of exogenous glucose supplementation on milk yield or DMI. However, this was a short-term infusion with little time for metabolic adaptation. An earlier study by Hurtaud et al. (1998) infused glucose into the duodenum of lactating dairy cows and examined effects on milk yield, milk composition, and plasma metabolites. That study reported that increasing the duodenal supply of glucose had no effect on milk yield, caused a modest increase in milk protein yield, but induced a marked decrease in milk fat yield (Hurtaud et al., 1998).

\section{Blood Metabolites and Hormones}

Lesser blood glucose concentrations during lactation would theoretically compromise the function of tissues that depend on glucose (Lucy et al., 2014). Blood metabolites such as FA and BHB, as well as the metabolic hormones insulin and IGF1, play an important role in controlling reproductive success. We detected no effect on plasma FA concentrations when animals were infused with glucose in the current study. It should be noted, however, that all the animals were in late lactation and positive energy balance; as a result, plasma FA concentrations were low in all animals. 


\section{Uterine Glucose}

Glucose uptake into fetal tissues is facilitated by glucose transporters that increase or decrease in expression in response to both acute and chronic changes in fetal glucose concentration and conditions of intrauterine growth restriction (Hay, 2006). No differences in endometrial gene expression of glucose transporters or in uterine luminal fluid glucose concentrations were observed in the current study. In sheep, the uterine environment during early pregnancy contains at least 3 times as much nutrients (including glucose, amino acids, ions, and electrolytes) compared with that of nonpregnant ewes (Gao et al., 2009). Facilitative glucose transport molecules are responsible for glucose transport across cellular membranes. Adequate glucose uptake and metabolism are essential for the proper differentiation of the endometrium toward a receptive state

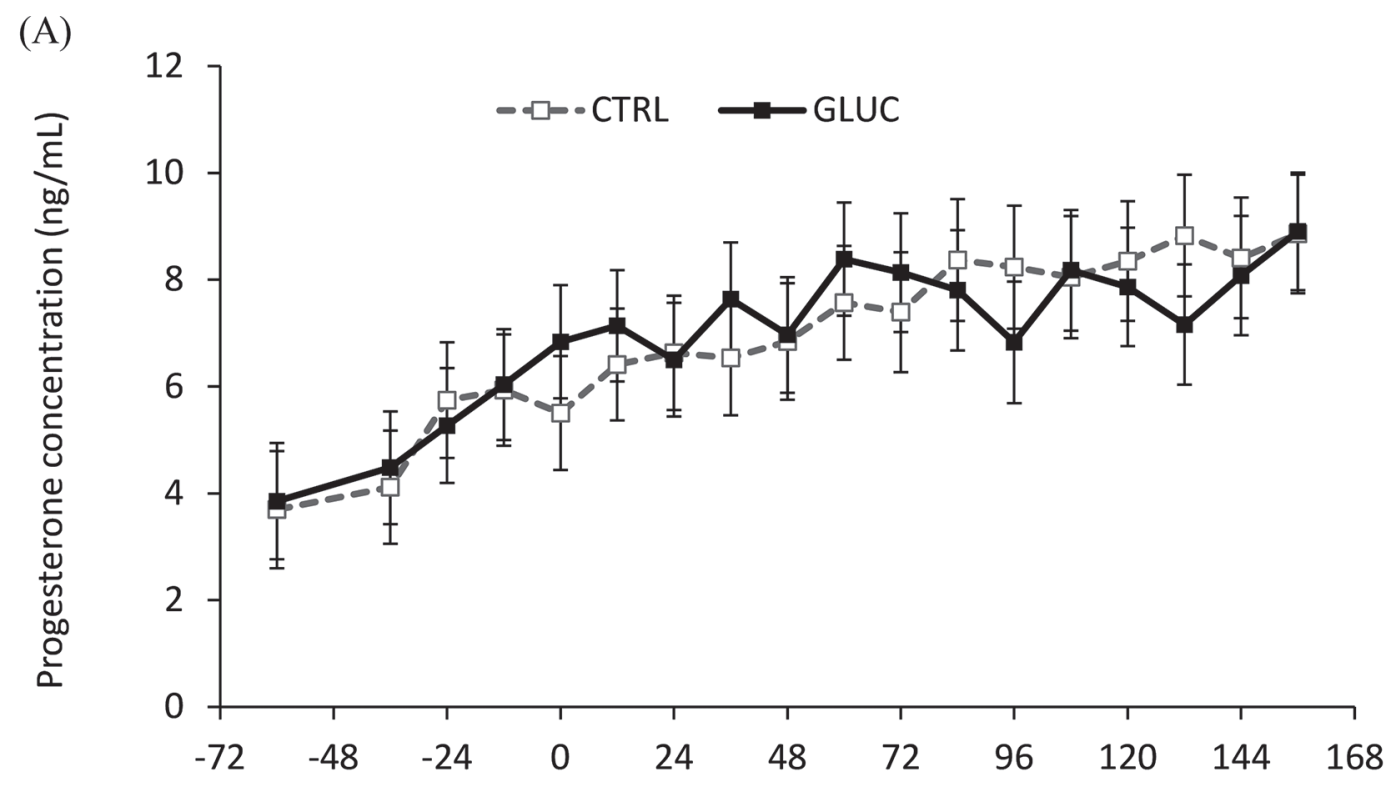

(B)

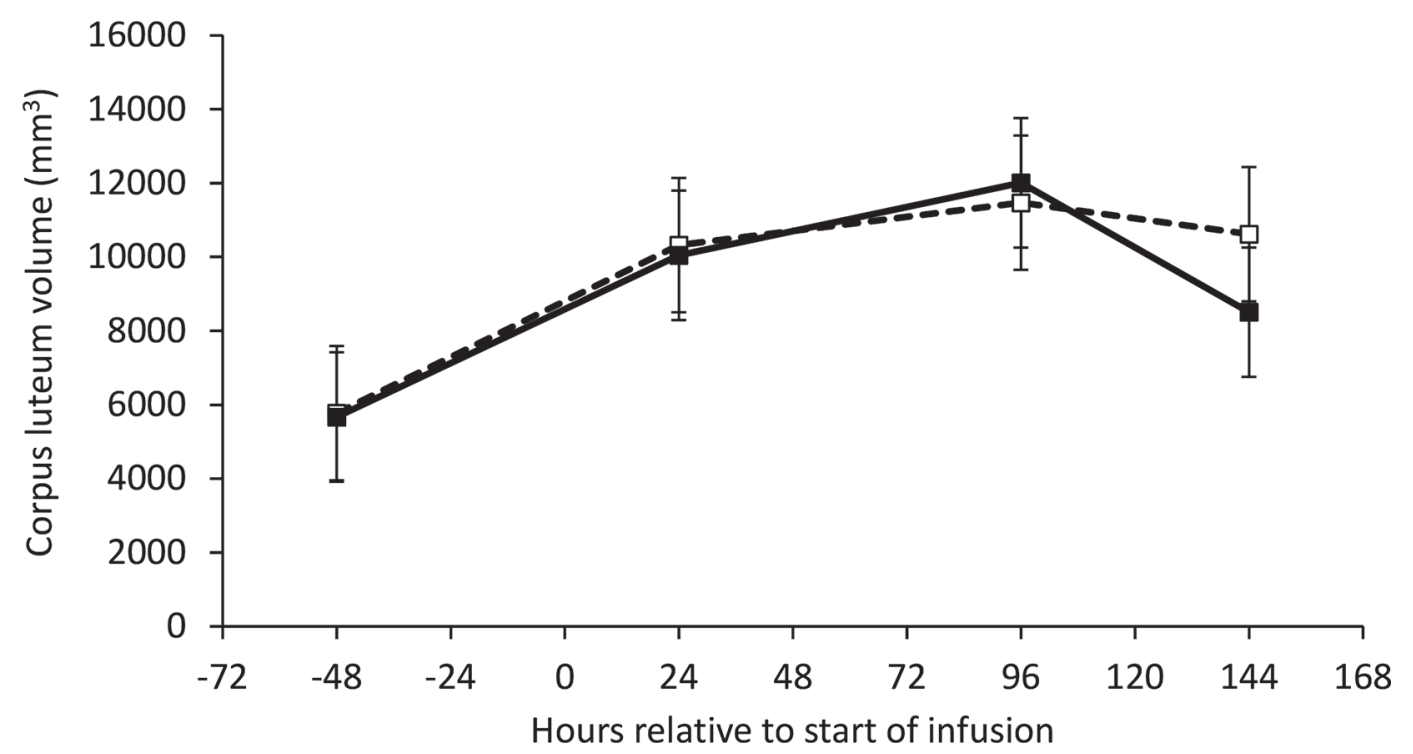

Figure 7. The effect of exogenous glucose infusion (GLUC) on progesterone concentrations and corpus luteum volume. The GLUC cows received intravenous glucose infusion $(750 \mathrm{~g} / \mathrm{d} ; 78 \mathrm{~mL} / \mathrm{h}$ of $40 \%$ glucose) at a constant rate from $0 \mathrm{~h}$ until $156 \mathrm{~h}$; the control (CTRL) cows received intravenous infusion of saline $(78 \mathrm{~mL} / \mathrm{h}$ of $0.9 \%$ saline solution). (A) There was no effect of treatment $(P=0.6)$ or treatment by time interaction $(P=0.5)$ on progesterone concentrations during the study period. (B) Corpus luteum tissue volume for GLUC and CTRL animals. There was no overall effect of treatment on corpus luteum volume $(P>0.05)$, but the treatment by time interaction was significant $(P<0.001)$. Vertical bars indicate SEM. 
capable of supporting embryo implantation; however, the role of glucose transporters in endometrial function remains poorly understood (Frolova and Moley, 2011). Although, at first glance, the lack of a treatment effect on uterine lumen glucose concentrations and endometrial glucose transporter expression is at odds with the elevated concentrations in blood, it should be noted that the time elapsed from the infusions ceasing to harvesting of the uterine lumen fluid samples was 6 to $8 \mathrm{~h}$. It is likely that circulating glucose would have returned to normal within 1 to $2 \mathrm{~h}$ of the pumps being turned off (Patton et al., 2009). Similarly, any available glucose may have been rapidly metabolized by the uterus and conceptuses.

\section{Progesterone Concentrations}

Progesterone is important for embryonic development and the establishment of pregnancy (Lonergan, 2011). The concentration of progesterone in the circulation is a balance between CL progesterone production and hepatic progesterone metabolism. Luteal tissue mass is a primary indicator of progesterone production (Wiltbank et al., 2011). Progesterone alters endometrial gene expression and stimulates uterine histotroph secretion, which is a primary source of nutrition for conceptus development (Forde et al., 2009). Lower circulating progesterone concentrations hinder embryonic development (Forde et al., 2011a, 2012) through effects on endometrial gene expression (Forde et al., 2009) and conceptus elongation (Clemente et al., 2009). We observed no effects of exogenous glucose on either CL development or circulating progesterone concentrations. This observation indicates that the exogenous glucose supplied had a detrimental effect on embryo development through a direct effect on either the embryo or the endometrium, or both, but this effect was independent of circulating P4 concentrations.

\section{CONCLUSIONS}

Infusing exogenous glucose increased blood glucose concentrations but decreased embryonic development during early pregnancy. Exogenous glucose infusion did not affect DMI, milk production, CL development, circulating progesterone concentrations, uterine lumen glucose concentrations, or the mRNA abundance of glucose transporters in endometrial tissue. Further investigation into the metabolism of glucose as an energy substrate and its potential effects on embryo development in later stages of gestation is required. We conclude that increasing circulating glucose concentrations may be detrimental to embryonic development in cows that are in positive energy balance.

\section{ACKNOWLEDGMENTS}

The authors thank the staff of Teagasc Moorepark (Fermoy, Ireland) for their co-operation, care, and management of the experimental cows. Funding was received from the Irish Department of Agriculture, Food and Marine (Dublin, Ireland) under competitive research grant RSF 13/S/528S; the European Union Seventh Framework Programs (FP7:2007-2013) under the grant agreement 311776 (PROLIFIC); and the Teagasc Walsh Fellowship scheme.

\section{REFERENCES}

Aschenbach, J. R., N. B. Kristensen, S. S. Donkin, H. M. Hammon, and G. B. Penner. 2010. Gluconeogenesis in dairy cows: The secret of making sweet milk from sour dough. IUBMB Life 62:869-877.

Bazer, F. W., J. Kim, G. Song, H. Ka, C. D. Tekwe, and G. Wu. 2012. Select nutrients, progesterone, and interferon tau affect conceptus metabolism and development. Ann. N. Y. Acad. Sci. 1271:88-96.

Bell, A. W. 1995. Regulation of organic nutrient metabolism during transition from late pregnancy to early lactation. J. Anim. Sci. $73: 2804-2819$.

Butler, S. T., A. L. Marr, S. H. Pelton, R. P. Radcliff, M. C. Lucy, and W. R. Butler. 2003. Insulin restores GH responsiveness during lactation-induced negative energy balance in dairy cattle: Effects on expression of IGF-I and GH receptor 1A. J. Endocrinol. 176:205-217

Cardoso, F. C., S. J. LeBlanc, M. R. Murphy, and J. K. Drackley. 2013. Prepartum nutritional strategy affects reproductive performance in dairy cows. J. Dairy Sci. 96:5859-5871.

Choi, Y.-H., I. C. Velez, B. Macías-García, F. L. Riera, C. S. Ballard, and K. Hinrichs. 2016. Effect of clinically-related factors on in vitro blastocyst development after equine ICSI. Theriogenology 85:1289-1296. https://doi.org/10.1016/j.theriogenology.2015.12 .015 .

Chomczynski, P., and N. Sacchi. 1987. Single-step method of RNA isolation by acid-guanidium thiocyanate-phenol-chloroform extraction. Anal. Biochem. 162:156-159.

Clemente, M., J. de La Fuente, T. Fair, A. Al Naib, A. Gutierrez-Adan, J. F. Roche, D. Rizos, and P. Lonergan. 2009. Progesterone and conceptus elongation in cattle: A direct effect on the embryo or an indirect effect via the endometrium? Reproduction 138:507-517.

Forde, N., M. E. Beltman, G. B. Duffy, P. Duffy, J. P. Mehta, P. Ó'Gaora, J. F. Roche, P. Lonergan, and M. A. Crowe. 2011a. Changes in the endometrial transcriptome during the bovine estrous cycle: effect of low circulating progesterone and consequences for conceptus elongation. Biol. Reprod. 84:266-278.

Forde, N., F. Carter, T. Fair, M. A. Crowe, A. C. Evans, T. E. Spencer, F. W. Bazer, R. McBride, M. P. Boland, P. O'Gaora, P. Lonergan, and J. F. Roche. 2009. Progesterone-regulated changes in endometrial gene expression contribute to advanced conceptus development in cattle. Biol. Reprod. 81:784-794.

Forde, N., F. Carter, T. E. Spencer, F. W. Bazer, O. Sandra, N. Mansouri-Attia, L. A. Okumu, P. A. McGettigan, J. P. Mehta, R. McBride, P. O'Gaora, J. F. Roche, and P. Lonergan. 2011 b. Conceptus-induced changes in the endometrial transcriptome: how soon does the cow know she is pregnant? Biol. Reprod. 85:144-156.

Forde, N., P. A. McGettigan, J. P. Mehta, L. O'Hara, S. Mamo, F. W Bazer, T. E. Spencer, and P. Lonergan. 2014a. Proteomic analysis of uterine fluid during the pre-implantation period of pregnancy in cattle. Reproduction 147:575-587.

Forde, N., J. P. Mehta, M. Minten, M. A. Crowe, J. F. Roche, T. E. Spencer, and P. Lonergan. 2012. Effects of low progesterone on the endometrial transcriptome in cattle. Biol. Reprod. 87:124.

Forde, N., A. O'Gorman, H. Whelan, P. Duffy, L. O'Hara, A. K. Kelly, V. Havlicek, U. Besenfelder, L. Brennan, and P. Lonergan. 2016. 
Lactation-induced changes in metabolic status and follicular-fluid metabolomic profile in postpartum dairy cows. Reprod. Fertil. Dev.28:1882-1892.

Forde, N., C. A. Simintiras, R. Sturmey, S. Mamo, A. K. Kelly, T. E. Spencer, F. W. Bazer, and P. Lonergan. 2014b. Amino acids in the uterine luminal fluid reflects the temporal changes in transporter expression in the endometrium and conceptus during early pregnancy in cattle. PLoS One 9:e100010.

Frolova, A. I., and K. H. Moley. 2011. Glucose transporters in the uterus: An analysis of tissue distribution and proposed physiological roles. Reproduction 142:211-220.

Gao, H., G. Wu, T. E. Spencer, G. A. Johnson, X. Li, and F. W. Bazer. 2009. Select nutrients in the ovine uterine lumen. I. Amino acids, glucose, and ions in uterine lumenal flushings of cyclic and pregnant ewes. Biol. Reprod. 80:86-93.

Gardner, D. K., and H. J. Leese. 1990. Concentrations of nutrients in mouse oviduct fluid and their effects on embryo development and metabolism in vitro. J. Reprod. Fertil. 88:361-368.

Gardner, D. K., P. L. Wale, R. Collins, and M. Lane. 2011. Glucose consumption of single post-compaction human embryos is predictive of embryo sex and live birth outcome. Hum. Reprod. 26:1981-1986.

Garverick, H. A., M. N. Harris, R. Vogel-Bluel, J. D. Sampson, J. Bader, W. R. Lamberson, J. N. Spain, M. C. Lucy, and R. S. Youngquist. 2013. Concentrations of nonesterified fatty acids and glucose in blood of periparturient dairy cows are indicative of pregnancy success at first insemination. J. Dairy Sci. 96:181-188.

Green, J. C., J. P. Meyer, A. M. Williams, E. M. Newsom, D. H. Keisler, and M. C. Lucy. 2012. Pregnancy development from day 28 to 42 of gestation in postpartum Holstein cows that were either milked (lactating) or not milked (not lactating) after calving. Reproduction 143:699-711.

Green, M. P., A. J. Harvey, L. D. Spate, K. Kimura, J. G. Thompson, and R. M. Roberts. 2016. The effects of 2,4-dinitrophenol and d-glucose concentration on the development, sex ratio, and interferon-tau (IFNT) production of bovine blastocysts. Mol. Reprod. Dev. 83:50-60. https://doi.org/10.1002/mrd.22590.

Guerif, F., P. McKeegan, H. J. Leese, and R. G. Sturmey. 2013. A simple approach for COnsumption and RElease (CORE) analysis of metabolic activity in single mammalian embryos. PLoS One 8:e67834.

Harvey, A. J., K. L. Kind, and J. G. Thompson. 2002. REDOX regulation of early embryo development. Reproduction 123:479-486.

Hay, W. W., Jr. 2006. Placental-fetal glucose exchange and fetal glucose metabolism. Trans. Am. Clin. Climatol. Assoc. 117:321-339, discussion 339-340.

Hurtaud, C., H. Rulquin, and R. Verite. 1998. Effects of graded duodenal infusions of glucose on yield and composition of milk from dairy cows. 1. Diets based on corn silage. J. Dairy Sci. 81:3239-3247.

Javed, M. H., and R. W. Wright Jr.. 1991. Determination of pentose phosphate and Embden-Meyerhof pathway activities in bovine embryos. Theriogenology 35:1029-1037.

Lane, M., and D. K. Gardner. 1996. Fertilization and early embryology: Selection of viable mouse blastocysts prior to transfer using a metabolic criterion. Hum. Reprod. 11:1975-1978.

Leese, H. J. 1983. Studies on the movement of glucose, pyruvate and lactate into the ampulla and isthmus of the rabbit oviduct. Q. J. Exp. Physiol. 68:89-96.

Leese, H. J. 2012. Metabolism of the preimplantation embryo: 40 years on. Reproduction 143:417-427.

Leese, H. J., and A. M. Barton. 1984. Pyruvate and glucose uptake by mouse ova and preimplantation embryos. J. Reprod. Fertil. 72:9-13.
Lonergan, P. 2011. Influence of progesterone on oocyte quality and embryo development in cows. Theriogenology 76:1594-1601.

Lucy, M. C., S. T. Butler, and H. A. Garverick. 2014. Endocrine and metabolic mechanisms linking postpartum glucose with early embryonic and foetal development in dairy cows. Animal 8(Suppl. 1):82-90.

Lucy, M. C., R. C. Escalante, D. H. Keisler, W. R. Lamberson, and D. J. Mathew. 2013. Short communication: Glucose infusion into early postpartum cows defines an upper physiological set point for blood glucose and causes rapid and reversible changes in blood hormones and metabolites. J. Dairy Sci. 96:5762-5768.

Maillo, V., D. Rizos, U. Besenfelder, V. Havlicek, A. K. Kelly, M. Garrett, and P. Lonergan. 2012. Influence of lactation on metabolic characteristics and embryo development in postpartum Holstein dairy cows. J. Dairy Sci. 95:3865-3876.

Moore, S. G., T. Fair, P. Lonergan, and S. T. Butler. 2014. Genetic merit for fertility traits in Holstein cows: IV. Transition period, uterine health, and resumption of cyclicity. J. Dairy Sci. 97:27402752 .

O'Hara, L., S. Scully, V. Maillo, A. K. Kelly, P. Duffy, F. Carter, N. Forde, D. Rizos, and P. Lonergan. 2012. Effect of follicular aspiration just before ovulation on corpus luteum characteristics, circulating progesterone concentrations and uterine receptivity in single-ovulating and superstimulated heifers. Reproduction 143:673-682.

Patton, J., D. A. Kenny, S. McNamara, J. F. Mee, F. P. O'Mara, M. G. Diskin, and J. J. Murphy. 2007. Relationships among milk production, energy balance, plasma analytes, and reproduction in Holstein-Friesian cows. J. Dairy Sci. 90:649-658.

Patton, J., J. J. Murphy, F. P. O'Mara, and S. T. Butler. 2009. Responses of North American and New Zealand strains of HolsteinFriesian dairy cattle to homeostatic challenges during early and mid-lactation. Animal 3:251-260.

Poston, L., R. Caleyachetty, S. Cnattingius, C. Corvalán, R. Uauy, S. Herring, and M. W. Gillman. 2016. Preconceptional and maternal obesity: Epidemiology and health consequences. Lancet Diabetes Endocrinol. 4:1025-1036.

Reynolds, C. K. 2005. Glucose balance in cattle. Florida Ruminant Nutrition Symp. Accessed Jul. 13, 2018. http://dairy.ifas.ufl.edu/ rns/2005/Reynolds.pdf.

Rieger, D., B. Grisart, E. Semple, A. Van Langendonckt, K. J. Betteridge, and F. Dessy. 1995. Comparison of the effects of oviductal cell co-culture and oviductal cell-conditioned medium on the development and metabolic activity of cattle embryos. J. Reprod. Fertil. 105:91-98.

Rieger, D., N. M. Loskutoff, and K. J. Betteridge. 1992. Developmentally related changes in the metabolism of glucose and glutamine by cattle embryos produced and co-cultured in vitro. J. Reprod. Fertil. 95:585-595.

Rizos, D., F. Carter, U. Besenfelder, V. Havlicek, and P. Lonergan. 2010. Contribution of the female reproductive tract to low fertility in postpartum lactating dairy cows. J. Dairy Sci. 93:1022-1029.

Smith, D. G., and R. G. Sturmey. 2013. Parallels between embryo and cancer cell metabolism. Biochem. Soc. Trans. 41:664-669.

Thompson, J. G., R. J. Partridge, F. D. Houghton, C. I. Cox, and H. J. Leese. 1996. Oxygen uptake and carbohydrate metabolism by in vitro derived bovine embryos. J. Reprod. Fertil. 106:299-306.

Wiltbank, M. C., A. H. Souza, P. D. Carvalho, R. W. Bender, and A B. Nascimento. 2011. Improving fertility to timed artificial insemination by manipulation of circulating progesterone concentrations in lactating dairy cattle. Reprod. Fertil. Dev. 24:238-243. 